\title{
Adaptive Control System of the Pumping Unit
}

\author{
A.N. Tsvetkov, A.R. Safin, I.V. Ivshin, T.I. Petrov, R.Sh. Misbakhov, V.Yu. Kornilov
}

\begin{abstract}
Rapid diagnosis of the pumping unit should ensure the identification of the main classes of malfunctions and, if possible, a quantitative assessment of the degree of malfunction in order to implement a short-term prediction of the technical condition.
\end{abstract}

Keywords: adaptive control, pumping unit, dynacard, wattmetrogram.

\section{RAPID DIAGNOSIS OF A PUMP UNIT USING A DYNAMOGRAM}

The figure of theoretical dynacard, which takes into account the influence of semi-fluid and hydrodynamic friction forces, as well as the inertia forces, differs from the parallelogram. The difference between the theoretical dynamogram and the practical one is the oscillatory process that occurs in the column of rods as a result of the uneven movement of the rod suspension point [1],[2]. Oscillations arise as a result from a combination of forced and natural vibrations of the rod string. These oscillations can be considered as additive interferences overlaid on the informative signal, and digital filtering techniques can be used to suppress them [3].

The following processing options exist:

Stage 1 - section of the dynacard during the course of the boom upwards undergoes a discrete Fourier transform and the parameters of the parasitic oscillatory process are determined.

Stage 2 - filtration the dynacard from vibrations by a digital filter.

Consequently, the resulting dynacard of the standard operation of the plant, obtained during all processing and filtering, has a symmetry, which is characteristic for the ideal dynacard [4].

The method of identification of dynacards is based on the calculation of difference curves - subtracting the curve of the section of the dynacard when the boom moves upwards from the inverted curve of the plot of the dynacard when the boom moves down, and the starting points of the sections are taken as zero levels. Replacing the dynamograms with their difference curves makes it easier to organize diagnostics of

Revised Manuscript Received on July 22, 2019.

A.N. Tsvetkov, Kazan State Energy University, 51, str. Krasnoselskaya, Kazan

A.R. Safin, Kazan State Energy University, 51, str. Krasnoselskaya, Kazan

I.V. Ivshin, Kazan State Energy University, 51, str. Krasnoselskaya, Kazan

T.I. Petrov, Kazan State Energy University, 51, str. Krasnoselskaya, Kazan

R.Sh. Misbakhov, Kazan State Energy University, 51, str. Krasnoselskaya, Kazan

V.Yu. Kornilov, Kazan State Energy University, 51, str. Krasnoselskaya, Kazan the pumping unit. When the difference curve deviates from the zero value segment, the place and direction of this change is a sign of the qualitative state of the object under consideration. It is convenient to form this sign as a code of a sequence of sections of a difference curve having a constant sign [5].

For a simple assessment of the quantitative indicator of the state of the pump, the coefficient $\mathrm{Kc}$ is introduced, which characterizes the symmetry of the dynacard and is the ratio of the length of the first sign portion of the difference curve to the length of the entire difference curve [6]. The linear relationship between the coefficient $\mathrm{Kc}$ and the coefficient of filling $\mathrm{Kn}$ allows to determine the degree of filling of the pump with a sufficient degree of accuracy.

There are following advantages of the method:

- it is non-critical to the scale of dynamograms and does not require zero level marks;

- it does not require knowledge and storage of additional information about the well;

- the method is invariant to the form of the original parameter - a dynacard or wattmetrogram;

- it allows you to quantify the status of the pumping system.

\section{RAPID DIAGNOSIS OF A PUMP INSTALLATION USING A WATTMETROGRAM}

Under some conditions (complete balanced pumping unit system, engine operation at standard characteristic values) wattmeter card is a dynacard, which has been launched on a time scale [7].And thus, for one period of the swing cycle, the wattmeter card has all the properties of the dynacard. The difference curve is formed by subtracting the first half-period of the wattmeter from the second without inverting the last, since it already contains the signs of the inverted curve of the second half-period of the dynacard [8].

The sequence code of sections of the difference curve of the dynacard and the wattmeter card with the fully balanced state of the pumping unit is the same for most states of the pumping unit. When the pumping unit is not fully balanced, the amplitude of one half-cycle will decrease, the other will increase, which may affect the code of the sequence of sections of the difference curve [9]. In this case, the ambiguity of the conformity of the shape of the difference curve to a certain state of the pumping unit is excluded by calculating the quasi-balanced wattmetrogram, based on the crank balancing.

\section{MULTIPARAMETER OPERATIONAL DIAGNOSTICS}

Simultaneous monitoring of a number of parameters allows increasing the reliability and accuracy of diagnosing a pumping unit. 
Adding to dynamometry a wattmetry allows revealing the complex of mechanical failures of the pumping unit, the state of the electric motor and calculating the parameters of the balance of the pumping unit. The leaks in the pipe and waxing can also be detected by measuring the instantaneous oil production, which is an additional advantage. The most effective, based on the requirement of a minimum of additional capital costs attributable to each additional recognition of the state of the pumping unit, is biparametric diagnostics (dynamometry and wattmetry).

Table 1 presents examples of recognizable states with three-parameter diagnostics (4 examples of operating modes, 17 versions of the mode in the full version).

Table- I: Examples of recognizable conditions in three-parameter diagnostics

\begin{tabular}{|c|c|c|c|c|}
\hline Dynamometry & Wattmetry & $\begin{array}{c}\text { Measurement of } \\
\text { the flow rate }\end{array}$ & $\begin{array}{c}\text { Diagnostic } \\
\text { output }\end{array}$ & Engine control signal \\
\hline Norm & Norm & Norm & Norm & - \\
\hline Sucker rod breakage & Imbalance & Pump starvation & $\begin{array}{c}\text { Sucker rod } \\
\text { breakage }\end{array}$ & $\begin{array}{c}\text { Work in s1 mode (with a } \\
\text { given number of swings) }\end{array}$ \\
\hline Plunger jamming & Imbalance & $\begin{array}{c}\text { Production rate } \\
\text { decline }\end{array}$ & Plunger jamming & $\begin{array}{c}\text { Stop the engine, sending a } \\
\text { message about the need for } \\
\text { repair }\end{array}$ \\
\hline Norm & Lack of balance & Norm & Lack of balance & Reduced swing speed \\
\hline
\end{tabular}

To determine the state of the object, the difference curve is calculated, processed and filtered, then the code of the sequence of sections of the difference curve is determined and compared with the reference set [10]. If there is no match, the corresponding filter parameters are changed and the filtering step is repeated. In this construction of the algorithm, the digital filter parameters should be selected taking into account the larger range of the oscillation frequency of the difference curve, due to the position of the oscillation process curves during the plunger up and down [11].

The algorithm consists in a sequential expansion of the region of zero values of the difference curve by equating to zero at each step of the sign sections whose length does not exceed a certain part of the length.

After each step, a code of a sequence of sections of the difference curve is formed [12]. The iteration steps continue until the sequence code of sections of the difference curve coincides with one of the model codes corresponding to the recognizable states of the pump installation.

An important task, the solution of which depends on the efficiency of the developed algorithm, is to determine the optimal parameters of a digital filter [13]. To determine these parameters, it is necessary to identify the dependence of the period of oscillations suppressed by the digital filter in the portions of the dynacard corresponding to the displacement of the plunger on the parameters of the pump-layer.

\section{THE ALGORITHM FOR CONTROL OF THE PUMP UNIT}

The algorithm for monitoring the efficiency of the pumping unit must ensure the identification of emergency and pre-emergency conditions. Emergency conditions are considered to be discontinuous (instantaneous) faults, - rod breaks, plunger jamming, reducer, connecting rod breakage, etc.

Malfunctions that cause a decrease in production by more than $50 \%$ are called pre-emergency (the so-called

\section{PROCESSING OF CONTROL RESULTS}

malfunctions with changes in parameters over time, with accumulation), they can include non-filling, leaks and others [14],[15]. A reasonable form of initial information for monitoring the efficiency of the pumping unit is the power consumed by the engine of the pumping unit.

A necessary criterion is how the area has changed in one swing period compared to the reference area of the wattmeter card. This criterion allows us to quantify the accumulating fault, thus separating the pre-emergency and emergency states.

Change of wattmetry area:

$$
\Delta S_{W}=S_{1}-S_{2}
$$

where $\mathrm{S} 1$ is the initial area;

$\mathrm{S} 2$ - the area at the moment.

The coefficient characterizing the change in area:

$$
k_{S}=\frac{\Delta S_{W}}{S_{1}}
$$

Approximately $\mathrm{ks}=0.25$ corresponds to the pump filling ratio $\mathrm{kn}=0.6 \div 0.4$, which can be characterized as a pre-emergency condition; $\mathrm{ks}=0.5$ corresponds to $\mathrm{kn} \approx 0$ or disruption of the supply as a result of failure of the discharge or receiving valve.

\section{CONCLUSION}

Thus, the types of operational diagnostics considered in the article, as part of an adaptive control station, make it possible to work more effectively with a pumping unit.

The algorithm for diagnostics by wattmeter cards and dynacards has been developed, a table of control signals for malfunctions and a method for processing the information obtained are presented.

\section{Conflict of interests}

The author confirms that the materials presented do not contain a conflict of interest. 


\section{ACKNOWLEDGMENTS}

The article was published as part of the project "Creating a Series of Electric Drives Based on Russian High-Performance Synchronous Motors for Oil Pumping Units Using Wireless Data Communication Systems and an Adaptive Control System for Smart Fields", Agreement No. 074-11-2018-020 with the Ministry of Education and Science of the Russian Federation May 30, 2018.

\section{REFERENCES}

1. Kalachev Yu.N. Vector regulation (practice notes). - EFO, 2013. - 63 p. (in Russian).

2. Trzynadlowski A.M., Kirlin R.L., Legowski S.F. Space vector PWM techniquewith minimumswitching losses and a variable pulse rate, IEEE Transactions on Industrioal Electronics, 1997.

3. Weinger A.M. Adjustable AC electric drives. / Summary of introductory lectures. M., 2009 - 102 p.(in Russian).

4. Pankratov VV, Zima EA Energy-optimal vector control of asynchronous electric drives: Proc. allowance. - Novosibirsk: Publishing house of NSTU, 2005. - 120 p.(inRussian).

5. Petrov, T.I., Safin, A.R., Ivshin, I.V., Tsvetkov, A.N., Kornilov, V.Y. The Prospects of Using a Synchronous Machine with Permanent Magnets in the Oil Industry (2018) 2018 14th International Scientific-Technical Conference on Actual Problems of Electronic Instrument Engineering, APEIE 2018 - Proceedings, article № 8546157, pp. 336-338

6. Shteinberg, S., Serezhin, L.P., Zalutskii, I.E.The way to design and exploit effective control systems(2004) Prom. Avtomat. Sist. Upr. Kontrollery, pp. 1-7.

7. Ulianov, S.S., Sagyndykov, R.I., Davydov, D.S., Nosov, S.A., Dolinyuk, V.Y., Ilyin, A.V. Making smart wells equipped with electric submersible pump units (2018) Neftyanoe Khozyaystvo - Oil Industry, 2018 (10), pp. 130-133.

8. Khakim'Yanov, M.I., Svetlakova, S.V., Guzeev, B.V.Comparative analysis of the possibilities of domestic and imported wells automation systems operated by SRP(2008) Neftegazovoe Delo= the Electronic Scientific Journal Oil and Gas Business, (2), pp. 1-22.

9. Sadov, V.B. The approach to definition of defects of sucker rod pump on dinacard (2016) Neftyanoe Khozyaystvo - Oil Industry, (2), pp. 90-93.

10. Zyuzev, A.M., Bubnov, M.V. Sucker-rod pumping unit balance diagnostics by wattmeter card (2019) Bulletin of the Tomsk Polytechnic University, Geo Assets Engineering, 330 (4), pp. 178-187.

11. Liu, X., Qi, Y., Wu, J., Yang, L., Chen, F.An approach to the optimum design of sucker-rod pumping system(2010) Proceedings - 2010 WASE International Conference on Information Engineering, ICIE 2010, 3, art. no. 5571696, pp. 140-143.

12. Lindh, T., Montonen, J.-H., Grachev, M., Niemela, M.Generating surface dynamometer cards for a sucker-rod pump by using frequency converter estimates and a process identification run (2015) International Conference on Power Engineering, Energy and Electrical Drives, 2015-September, art. no. 7266353, pp. 416-420.

13. Dong, S., Cui, Y., Xing, M., Liao, S., Du, L.The dynamic simulation model and the comprehensive simulation algorithm of the beam pumping system (2013) Proceedings - 2013 International Conference on Mechanical and Automation Engineering, MAEE 2013, art. no. 6602152, pp. 118-122.

14. Fozao, K.F., Lissouck, M., Lontsi, F., Ngasa, A., Mbanda, N.Hands-on model of sucker rod pumping facility for oil well production(2015) Journal of Petroleum and Gas Engineering, (6), pp. 45-53.

15. Wang, F., Chen, G.The virtual experiment system of sucker-rod pumping development and its application(2010) 2010 International Conference on Computing, Control and Industrial Engineering, CCIE 2010, 2, art. no. 5491941, pp. 178-181. 